\title{
The Children of Leviathan: Psychoanalytic Speculations Concerning Welfare Law and Punitive Sanctions
}

\author{
Bernard L. Diamond*
}

\section{$\mathrm{T}$} HE ENGRAVED TITLEPAGE of the first edition of Hobbes' Leviathan, publislied in 1651, portrays the State as a giant man, looming over the countryside. On close inspection, this giant may be seen to be the synthesis of a multitude of individual human beings. But in the aggregate, the Leviathan is simply a giant replica of its tiny human components.

The temptation is very great to anthropomorphize a political entity like the State or a social institution like the Law. If such social organizations are but gigantic replications of the individual, numerous inferences and deductions can be made about their structure and function. The natural laws of human biology automatically apply, and one may predict the course of the social institution in history according to the same rules with which one predicts the lifetime course of the human. Thus, governments, social institutions, indeed, whole cultures undergo an autonomous biological development--birth, childhood, maturity, old age, and death and dissolution in the same inevitable sequence as is predestined for the individual organism.

Having succumbed to the basic temptation of anthropomorphism in form and structure, it is very easy to progress to the next stage: the assumption of identity of pathology between the individual creature and the social aggregation, function, or institution. Medicine, particularly psychiatry, is adept in supplying the vocabulary for such anthropomorphisms. We speak glibly of "sick" and of "healthy" economies; because schizophrenia is a disease of the mind cliaracterized by fragmentation and internal division of the ego, so a nation divided against itself is "schizophrenic." The complex maneuverings of national foreign policies are described in terms appropriate to the sparring of two maladjusted adolescents. It is a sad fact that such anthropomorphisms are not recognized as mere metaphors and analogies but are used by people everywhere, including some scholars and politicians, as the basis for comprehension, appraisal, prediction, and mampulation of social and cultural structures.

Psychoanalysis, much more than other schools of psychiatry, is par-

*A.B., 1935, M.D., 1939, University of California. Professor of Law and of Criminology, University of California, Berkeley. 
ticularly enticing in its potential applicability to social entities. Psychoanalysis is concerned with the most basic of all human psychological forces: sex and aggression, love and hate. Psychoanalysis is preoccupied with the origin, growth and development, and ultimate expression of these deep human drives. Sex and aggression are conceived of as innate biological forces which undergo an incredibly varied series of transformations before they manifest themselves in their adult mature forms. Detrimental influences, both intra and extrapsychic, affect the development and vicissitudes of these biological drives. If the noxious influences are not overcoine, psychopathology results. The symptoms of the resultant psychopathological states are explainable as consequences of the dynamic interaction of the pathological drives and the defenses of the ego. In short, the psychodynamic mechanisms explain and account for the manifestations of psychical disease, and these same mechanisms provide the means for the remedial process through the techniques of psychoanalytic therapy.

There have been many attempts to apply psychoanalytic theories and climical knowledge to social problems. The inost famous is, of course, Freud's small monograph, Civilization and Its Discontents, first published in 1929. Freud rather casually presents a number of admittedly speculative ideas as to the inherent opposition of culture and social organization to the instinctual gratification (happiness) of the individual. Throughout the essay, Freud is unabashedly anthropomorphic in his analogies between the development and pathology of society and that of the individual. He states: "[W] . . . have recognized the evolution of culture as a special process, comparable to the normal growth of an individual to maturity ...." Again: "The analogy between the process of cultural evolution and the path of individual development may be carried further in an important respect." He follows with: "Another point of agreement is that the cultural super-ego, just like that of an individual, sets up high ideals and standards, and that failure to fulfill them is punished by both with 'anxiety of conscience.' "3 Finally, Freud concludes with his social diagnosis: "If the evolution of civilization has such a farreaching similarity with the development of an individual, and if the same methods are employed in both, would not the diagnosis be justified that many systems of civilization-or epochs of it-possibly even the whole of humanity-have become 'neurotic' under the pressure of the civilizing trends?"4

\footnotetext{
1 Fretd, Civmization and Its Discontents 64 (Riviere transl. 1930).

2 Id. at 136 .

3 Id. at 137 .

4 Id. at 141 .
} 
Freud's mild and undogmatic little essay immediately became the focal point of bitter controversy. To the psychoanalyst, Freud's excursion into sociology was taken to grant unrestricted license to diagnose all that ails society as if whole cultures were but individual patients on the analytic couch. To others, the discovery that there existed other biological responses related to social development of animals, such as "territoriality," or evidence (of which there is a good deal) that aggression is not necessarily biologically innate in all living creatures as Freud postulated, provided the grounds for a triumphant denunciation of all psychoanalytic theory and method.

One ludicrous consequence of taking Freud's book so seriously was the total banishment of all psychoanalytic theory and practice from Soviet Russian psychiatry. Freud expressed some pessimistic predictions that he did not expect that even the utopian Marxist society with its abolition of private property would eliminate all problems of aggression and individual unhappiness from the world. ${ }^{5}$ Such views were sufficient to label psychoanalysis as anti-Marxist and exclude a whole discipline of psychological knowledge from a major portion of the civilized world.

It is unfortunate that all concerned with these subsequent bitter conflicts did not pay more attention to Freud's warning. He emphatically cautions:

\begin{abstract}
But it behoves us to be very careful, not to forget that after all we are dealing only with analogies, and that it is dangerous, not only with men but also with concepts, to drag them out of the region where they originated and have matured. The diagnosis of collective neuroses, moreover, will be confronted by a special difficulty. In the neurosis of an individual we can use as a starting-point the contrast presented to us between the patient and his environment which we assume to be "normal." No such background as this would be available for any society similarly affected; it would have to be supplied in some other way. And with regard to any therapeutic application of our knowledge, what would be the use of the most acute analysis of social neuroses, since no one possesses power to compel the community to adopt the therapy? ${ }^{6}$
\end{abstract}

Social institutions cannot be properly diagnosed as simply collective obsessional neuroses, nor can it be reasonably expected that psychoanalytic insight will result in desirable social change. Nevertheless, I think that certain aspects of psychoanalytic methodology-certain ways of looking at and investigating human problems-have a most fruitful application to the understanding of social issues. With full awareness of Freud's warning that we are only dealing with analogies, I shall apply

\footnotetext{
5Id. at 88-91.

${ }^{6}$ Id. at $141-42$.
} 
certain psychoanalytic methods of reasoning to some of the problems included in this symposium.

Jacobus tenBroek has recently published an extraordinarily exhaustive and scholarly analysis of California's dual system of family law. ${ }^{7}$ tenBroek traces our present conflicted, inconsistent, punitive, and discriminatory welfare laws to their origin in the Elizabethan Poor Law of $1601 .^{8}$ He fully documents the close relationslip between criminal sanctions and welfare aid to the poor. He describes in detail how society, as soon as it assumed the burden of providing welfare aid through governmental channels, accompanied this aid with punitive sanctions, usually of a highly discriminatory character. Thus today, our society relieves the misery of the poor and dependent with its riglit hand and takes away security with its left hand through imposition of criminal or other punitive sanctions contingent upon grants of such welfare aid. How can one explain this ambivalent attitude towards the poor? What can possibly explain this monstrous contradiction of social morality?

tenBroek's explanation is simple and direct:

Today in California, no less than in Elizabetban England, the family law of the poor derives its particular content and special nature from the central concept of the poor law system: public provision for the care and support of the poor. He who pays the bill can attach conditions, related or unrelated to the purpose of the grant, and almost always does. ... The basic motive, thus, once the original step is taken, is fiscal and economic: to conserve public funds to the fullest extent possible consistent with the original undertaking. Althougl this fundamental motive from time to time has been augmented by the punitive, the moralistic, the political, and restrained by the humane and the rehabilitative, it has been determinative in molding the character and fixing the features of the law of the poor in general and the family law of the poor in particular. ${ }^{9}$

As a psychoanalyst, $I$ find it difficult to accept tenBroek's economic motive as the basic dynamic force behind the malignant social symptom of ambivalence towards the poor and dependent. I find it hard to beheve that concern over money alone can cause, in tenBroek's words, "Californians to associate welfare with punitive, repressive, discriminatory, exclusionary goals as well as with relief and rehabilitation. ${ }^{10}$ More is required to explain this phenomenon. For as tenBroek says, "When problems of poverty are handled under the police powers of the Constitu-

7 tenBroek, California's Dual System of Family Law: Its Origin, Developnent, and Present Status (pts. 1-3), 16 StaN. L. REv. 257, 900; 17 STAN. L. Rev. 614 (1964-65).

843 Eliz. 1, c. 2 (1601).

9 tenBroek, California's Dual System of Family Law: Its Origin, Development, and Present Status, 17 Star. L. REv. 614, 676-77 (1965).

10 Id. at 680 . 
tion, poverty comes to be equated with disease, immorality, and disorder. Indeed, historically these were inseparable conditions."11

When a psychoanalyst attempts to analyze a neurotic symptom, he follows a definite chain of reasoning utilizing certain assumptions which are basic to the psychoanalytic theory of neurosis: (1) He assumes that the symptoms have meaning and purpose, no matter what their apparent irrationality and seeming lack of sensible purpose; that the symptoms, no matter how contradictory, confused, paradoxical, or inconsistent, bear a primitive, symbolic, and always meaningful relationship to the infantile conflict out of which the symptoms developed. (2) That the symptoms accomplisl specific benefits for the patient, despite the pain and suffering which result. In other words, in the psychic economy of the personality, the symptoms show a net profit. (3) That the benefit or profit to the patient which is derived from the symptoms is of two orders: secondary gain, which is the conscious, or easily made conscious, contemporary motive for the symptoms; and prinary gain, which is the deeper, infantile, unconscious, and repressed motive. (4) That because of the primary gain, there is an investment of energy (cathexis) in the formation of a symptom which impels the patient to resist giving up the symptom, even when the secondary gain has diminished.

If one analyzes the present day welfare laws $a s$ if they were symptoms of a social neurosis, utilizing assunptions analogous to those described above for the comprehension of the neurotic symptoms of an individual, one can immediately inake soine speculative inferences. The validity of these inferences is, of course, not at all established. But they should be considered and may, perhaps, provide clues to further social and historical research.

The intensely ambivalent quality of the social attitudes behind our welfare laws indicates that these attitudes arise out of very old (that is, culturally infantile) conflicts concerned with primitive emotions and fears. The obvious emotions are love and hate. Thus society simultaneously loves and hates its poor, its dependent, and its disabled. The emotion of love requires that the poor and weak be protected, nurtured, and provided for, as if they were lielpless children. Failure to do so would cause collective guilt which would prevent those who have from enjoying what they have, knowing that others have not. Our love for the poor arises out of guilt rather than compassion. Our acts of charity, both as individuals and as the collective family of the state, are thus primarily for our benefit rather than for the benefit of the recipient. tenBroek is quite right in stating, "They [welfare programs] are designed 
to safeguard health, safety, morals, and well-being of the fortunate rather than directly to improve the lot of the unfortunate."12

The concurrent hatred implies fear-deep, primitive, unconscious fear-that the very existence of the poor and weak in society threatens the existence of that society. Punitive sanctions must then be applied to control those whom one fears, to make certain that they do not grow and prosper and gain the strength to fulfill their threat of usurpation of power. As the imdividual most fears death and annihilation, so society most fears anarchy and revolution. The poor and dependent, as a class, become endowed with magical, destructive powers totally out of proportion to reahty. They become sacrificial recipients of scapegoated sins, but at the same time they are tabooed objects who cannot be destroyed without dire consequences.

The poor and the disabled are thus like the insane, idiots, and children (and, in some societies, slaves and women) in being nonpersons. Nonpersons may be understood as those individuals in any society who, as a class, are defined differently in their social functions, privileges, and opportunities than those who are predominant in the society. A nonperson may occasionally be given special consideration (such as the relief from criminal responsibility for the insane), but in most instances the nonperson is sharply cut off from the major benefits to be derived from the society. Particularly, the nonperson is not allowed the privilege of having a say (in the sense of wielding power) over his own destiny or that of the society in which he hives. Yet he is not extruded from society, but must be retained, cared for, and nurtured.

There seems to be no historical precedent against exploitation of the nonperson for the benefit of the more potent members of society. In fact, such exploitation of nonpersons, be they insane, children, poor, or crippled, has been a constant feature of most societies. But their direct destruction has been tabooed except in a very few, atypical cultures (for example, Nazi Germany).

In a recent paper by Platt and myself, ${ }^{13}$ we have shown that from ancient times, the social and legal atttitudes toward the criminal responsibility of the insane have been closely associated with deepseated attitudes towards the child, who is regarded simultaneously as a helpless being to be loved and nurtured and as a wild beast to be curbed and tamed. We were able to demonstrate that the current tests of criminal responsibitity of the insane are derived from tests earlier applied to the child. The historical correctness of this legal association of both the

$12 I d$. at 681 .

13 Platt \& Diamond, The Origins and Development of the "Wild Beast" Concept of Mental Illness and Its Relation to Theories of Criminal Responsibility, $1 \mathrm{~J}$. OF THE HISTORY of the BeHavioral ScIENCES 355 (1965). 
insane and the child with the ambivalent attributes of the feared wild beast and the loved, helpless infant is amply documented.

In a second paper, ${ }^{14}$ we trace the familiar "right and wrong" test of criminal responsibility back to its ultimate mythological source in the story of Genesis, where the ingestion of the fruit of the tree of the knowledge of good and evil transforms the child-like and innocent (hence, nonperson) Adam and Eve into mortal, sinful human beings.

Professor tenBroek's extensive documentation ${ }^{15}$ of the development of our system of family and welfare law seems, in my opinion, to support a similar ambivalent position in society of the poor, the blind, the disabled, and the dependent, so that they, like the insane and children, are nonpersons.

Psychoanalytic theory of neurosis postulates the Oedipal conflict as the focal point, the critical period, in the development of the child. Failure to resolve the Oedipal conflict in socially acceptable patterns leads to residues of infantile sexual conflicts which persist into adulthood and force the development of neurotic ego defenses which are then expressed in symptom formation. The Oedipal conflict presupposes a state of ambivalent conflict between parent and child. The sexual instinct for propagation of the race demands that the young be loved and provided for. But the growth and development of each child also competitively threatens the survival of the parent. Each father is the potential victim of his own son. Freud speculated that the origin of this universal Oedipal phase of childhood development derives from dimly perceived racial memories of some universal prehistoric society where the sons literally did rise up and slay their fathers. ${ }^{16}$

Freud's theory of primitive society has never been substantiated by anthropological research, and the universality of the Oedipal conflict in all cultures at all times is certainly open to question. But there is ample clinical evidence to demonstrate that ambivalent attitudes of love and hate between parent and child are exceedingly wide-spread in a large variety of cultures, and that, at least in our western culture, these attitudes are at the root of subsequent neurotic conflict and symptom formation.

Viewed in this light, and carrying psychoanalytic speculation farther, all nonpersons - children, the poor, the disabled, the disenfranclised, the discriminated against minority, the criminal, the sinful, the slave (real or economic), and in some instances the woman-symbohically represent the child in a large-scale Oedipal struggle with the potent and socially

\footnotetext{
14 Platt \& Diamond, The Origins of the "Right and Wrong" Test and Its Subsequent Development in the United States, 54 CaIrr. L. Rev. (1966) (to be published).

15 tenBroek, supra note 7.

16 FreUd, Totear and Taboo passim (Brill transl. 1918).
} 
integrated members of society who collectively symbolize the father. This Leviathan father replicates on the larger social scale the intensely ambivalent attitudes towards society's children-the varied types of nonpersons-that the individual father has towards his own child. The law thus becomes the formal expression of this collective Oedipal neurosis.

What might be the "neurotic" benefits, real or imagined, concealed within the legally formalized, ambivalent attitudes towards the socially incapacitated? How does society profit from treating its welfare recipients simultaneously with aid and with pumishment? Here, I speculate, there must be achieved a delicate balance between acceptance and rejection. Clearly, if society were simply to reject, to allow its poor and disabled to starve, to be completely cast out from the community, it would mean the complete renunciation of our most ancient Judaeo-Christian ideals of morality and civilized behavior: "Am I my brother's keeper?"17 and " $[\mathrm{T}]$ hou shalt love they neighbour as thyself"18 from the Old Testament, and "Therefore all things whatsoever ye would that men should do to you, do ye even so to them"19 from the New Testament. It would be impossible to even conceive of such total renunciation of traditional ideals if it were not for the brutal fact that we liave experienced within our own hfetime such naked examples in totalitarian societies. But barring such extraordinary historical exceptions, a peaceful, civilized society must, individually and collectively, incorporate attitudes of compassion, nurture, and love towards its less fortunate members. One might even postulate that there exists in the collective, social mind an inner drive towards the utopian welfare state analogous to the instinctual inner drive of the individual psyche. Such a trend has certainly been a deep and ancient social ideal.

There exist, however, strong forces in opposition. If the welfare state is one ideal, individual responsibility, initiative, and competition represent another. This ideal, too, is deep and ancient, and it takes many forms: from the early theological concept of free will to the modern economic doctrine of free enterprise. Man is a responsible, free agent, answerable to God and mankind for his actions. If he fails in his social obligations, either througin simfulness, poverty, or disability, it is his own doing. He must not only suffer the consequences of his deviancy, but he must be punished as a moral lesson for those who have not yet failed or who miglit be tempted to renounce their social obligations.

The ideal of individual responsibitity and initiative favors the strong

17 Genesis 4:9 (King James).

18 Leviticus 19:18 (King James). The passage also appears in the New Testament. Matthew 22:39 (King James).

19 Matthew 7:12 (King James). 
and the powerful: those that have, as against those that have not. It implies a Darwinian struggle for social survival: a struggle to the death between the fit and the unfit. The nonperson, be he poor, disabled, criminal, insane, or simply a child, is the inevitable enemy of the person. The nonperson threatens the very existence of the person. He is unconciously perceived to threaten the person's possessions, his powers, and his values-even his ultimate survival.

It seems that our traditional welfare laws and policies achieve an insecure balance of forces. They are ordinarily effective in maintaining the status quo, but the balance is always precarious in two senses: (1) Those that have not-the nonpersons-may at any moment rise up and take what they need from those that have (thus, revolution and anarchy); and (2) the ranks of those that liave may desert to the enemy. That is, those that have may regard conformity to society's mores and the renunciation of their individual gratifications too high a price for the social benefits they are supposed to achieve. They may come to regard the ideal of individual responsibility and self-reliance as a fraud and a hoax whose practical benefits may never materialize or whose goals are too arduous to aspire towards.

Viewed in this light, compassion towards the nonperson and literal application of the Biblical injunctions is very dangerous. It threatens revolution at its worst; it undermines the value systems of the establislment at its best.

The solution-a typically neurotic one, in my opmion-is to compromise by both giving to and oppressing the nonpersons. Our society, through its welfare policies, is compassionate towards them. It provides aid and nurture, but only to the degree that it ensures that they remain nonpersons. Nonpersons must not be allowed to suffer to the point where they miglit be tempted to reverse the social order. At the same time they must be constantly reminded, througl the infliction of punitive sanctions and discriminatory exclusions, that they are nonpersons. They must be living examples to all who might be tempted to renounce their social obligations and join the ranks. All valid persons in society must be constantly reminded that desertion to the enemy means only humiliation, misery, pain, and suffering.

The secondary gain of this neurotic compromise is, as tenBroek describes, ${ }^{20}$ economic. The financial cost of society's institutionalized charity and compassion is kept to a reasonable minimum.

But beneath this superficial and quite consciously intended economic motivation, there must exist a more powerful, unconscious conflict of

20 tenBroek, supra note 9 , at 676. 
forces which is concerned with the very existence of the social order. These forces, arising out of the infancy of our social development, elicit defensive compromises which make sense only when viewed in a historical perspective. The primary gain of the social neurosis is to hold these conflicting forces in check, to maintain the balance, and to avoid the annihilation of the social order and its accompanying value systems. In this sense, we have the Oedipal struggle between parent and child on the grand scale of the Leviathan.

Psychoanalytic therapy is based on the major assumption that the neurotic symptom is archaic. The symptom is thought of as a defense of the ego against threatening emotional forces (for example, castration fear) which were very real and immediate during the early developmental period of the child. The erection of the neurotic ego defenses, no matter how disabling or how painful, was an urgent and necessary process at the time of their original construction. The ego, in its youthful instability, does not possess the strength nor the rationality to defend itself in less pathological ways when confronted with overwhelming conflict. The child has not yet learned all of the tricks, strategies, and techniques of the adult for getting out from under oppressive emotional conflict with minimum expense to one's self and with minimum loss of self-esteem. These are modes of adaptation which are available only to the mature adult who has acquired them through a long process of trial-and-error learning.

However, the neurotic defenses of the child's immature ego become autonomous and persist long after the need for them is urgent and necessary. The neurotic defenses make no allowance for the otherwise growing strength of the ego as the child develops into the adolescent and adult. It is probable that the very existence of certain types of neurotic defenses deprives the growing ego, no matter how strong, from acquiring the necessary skill and learning experience to utilize more normal means of coping with emotional adversity-especially with anxiety and fear arising out of internal sexual and aggressive impulses. In other words, the neurotic ego defense protects the child, but it also impedes further emotional development and the acquisition of more effective 1 defenses suitable to the stronger ego of the adult. The neurotic adult is, therefore, utilizing defense mechanisms which are designed to protect against the dangers of a past age. The neurotic symptoms are compromises in a struggle that may have little relevance to the external realities of the adult's world. They impede and constrict the functioning of the adult ego so that the significant struggles of the real world are neglected or evaded.

A neurotic defense is like the high wall around a medieval city. The 
wall originally was necessary: It defined the boundaries of the city, it gave the city a sense of solidarity and substance as an integrated social unit, and it protected against the outside marauders who were enemies of the city. But as the city grows, it outstrips its boundaries; its enemies in the surrounding countryside have long since disappeared, or perhaps been incorporated into the city. Now the wall serves only to strangle traffic, to create slums, and to impede further growth. Yet the wall is there; adaptations to its existence have been made. Certain elements of the city have a vested interest in the existence of the wall. It would be expensive to tear it down, and there would be disputes as to what should occupy the land upon which it stood. Further, the wall, as archaic and useless as it may be, gives a certain character to the city; it is an important part of the city's identity. To tear the wall down would change the very nature of the city.

So it is with neurotic symptoms. And so it is, I believe, with "neurotic" social defenses. The immature society-economically insecure, unstable in government, with the threat of anarchy and revolution very real, and whose ideological values and social ideals are only tentatively formed and incompletely accepted—such a society can be excused for its irrational welfare pohicies.

Elizabethan Poor Law of $1601^{21}$ was undoubtedly appropriate to the English society of the time. It is not so appropriate to a ricli, powerful, secure, and mature nation such as the United States. We, as a nation, are strong enough in our economic and social development to permit us to relinquish our ambivalent attitudes toward the recipients of our welfare aid. Our democratic social order is no longer vulnerable to sudden overturn. Our affluence is so great that no amount of sliaring of the wealth is going to allow the have-not nonpersons-our social clildren-to overthrow those who have and those who belong. The valid persons of our society need not fear the corruption of their ideals and ideologies by the outsiders. It is not necessary that aid to the families of needy children be accompanied by discriminatory, punitive sanctions and harsh moral regulations to save us fron "creeping socialism." It is not necessary to fear that poverty programs will destroy our system of free enterprise or that welfare assistance to the unemployed aged given in a manner which enhances, rather than degrades, the sense of individual worth and dignity will corrupt our ideal of individual responsibility and initiative. Our national ego is strong, and we can afford to give up our social neuroses.

Nevertheless, resistance to improvement is to be expected. Social

2143 Eliz. 1, c. 2 (1601). 
neuroses are as heavily cathected as are individual neuroses. They represent too much of an emotional investment to be easily relinquished; they represent too large a component of our social identity. Thus each new recommendation to diminish the punitive ambivalence of our welfare policies will be met with extremist fears of socialism, communism, subversion, and destruction of our moral values and our ideals of individual responsibility.

The extremist will demand that with every dollar of welfare aid, there must also go a measure of social degradation, of restriction of personal freedom, and of punitive sanctions. He will threaten that it is subversive to do otherwise. Such an attitude must be exposed as the social paranoia that it is and as a neurotic resistance against the development of the mature society in which all may participate with individual dignity.

By now, the reader can perceive that I have done precisely what I warned against earher: that is, fully anthropomorphized social attitudes and the legal expression of those attitudes as if they were the neurotic symptoms of an imdividual. Such psychoanalytic speculations are not intended as historical or scientific facts, but rather as a speculative, conceptual framework on which to order a wide diversity of social and historical information concerning a collection of highly disparate classes of individuals whose common denominator is that they occupy a marginal position in society and are the recipients of highly ambivalent social attitudes.

The interesting possibility exists, however, that the goal to be achieved is independent of the theoretical conceptualizations which serve to define the goal. A psychoanalyst might define our present social welfare dilemma as if it were a neurotic sickness. Sociologists, lawyers, or welfare specialists might prefer a completely different theoretical orientation. Certamly, the Marxist would prefer his own theories. And the conservative, rugged individualist Republican would have a different framework in which to structure his view of these matters.

But could there not be a consensual agreement among all that the goal is inherent in the very nature of man and his culture? The goal of the child is to grow up-to become an adult, a valid member of a social group with authentic relationships to others of that group. Social institutions, including the criminal law and family law, should facilitate this process and further the integration of the adult-to-be with his individual family, his community, his nation, and most of all, the family of all mankind.

The goal of social welfare legislation can be similarly defined. Its purpose is to make persons out of nonpersons. To transform Leviathan's 
children into adults; to validate them as full participating members of the social order, with all the rights, privileges, benefits, and obligations that accompany full citizenship. Anything short of that goal must be regarded as a failure. 